\title{
$\sqrt{P} \mid$
}

\section{HEALTH AND HUMAN SCIENCES}

\section{Toxicity Interaction of the Two Most Common Agricultural Herbicides in the United States: Glyphosate and Atrazine}

\section{Student researcher: Lauren E. Brulinski, Senior}

Glyphosate and atrazine are the two most common agricultural herbicides in the United States. These herbicides are sprayed on crops to reduce weed populations but move into drinking water sources following rain events. They are both controversial because of suspected hazardous health effects. The U.S. Environmental Protection Agency established the maximum contaminant level (MCL) of glyphosate in drinking water at $700 \mathrm{ppb}(\mu \mathrm{g} / \mathrm{L})$, and the International Agency for Research on Cancer, in "IARC Monographs Volume 112: Evaluation of Five Organophosphate Insecticides and Herbicides" (2015), designated glyphosate as "probably carcinogenic to humans." Atrazine is also suspected of being a carcinogen, but its main health concern is endocrine disruption. Atrazine's MCL is $3 \mathrm{ppb}$. Though there are countless studies concerning the individual toxicity of these herbicides, there is limited research on the potential toxic interaction, making this a substantial gap in our knowledge.
This study aims to test the hypothesis that a toxicity interaction occurs between glyphosate and atrazine at treatment concentrations below those observed for the single chemical exposure. In order to observe toxicity interactions, zebrafish were employed as a model organism. They were bred, and their embryos immediately collected and exposed to $0 \mathrm{ppb}, 3 \mathrm{ppb}$ atrazine, $700 \mathrm{ppb}$ glyphosate, or a $3 \mathrm{ppb}$ atrazine and $700 \mathrm{ppb}$ glyphosate mixture. At 120 hours post fertilization the behavior results showed that the $700 \mathrm{ppb}$ glyphosate and mixture treatment groups were significantly different from the control $(\mathrm{p}<0.05 ; \mathrm{n}=4$ with 24 subsamples/biological replicate). The morphological data including total larval length, head length, head width, and brain length were not significantly different from the control ( $\mathrm{p}>0.05 ; \mathrm{n}=7$ with $11-12$ subsamples/biological replicate).

Research advisor Jennifer Freeman writes: "Lauren's research project is providing the first information on toxicity of a mixture of the two most common herbicides applied in the United States. Her work is significant because both of these herbicides contaminate drinking water, resulting in a risk for human exposure." 

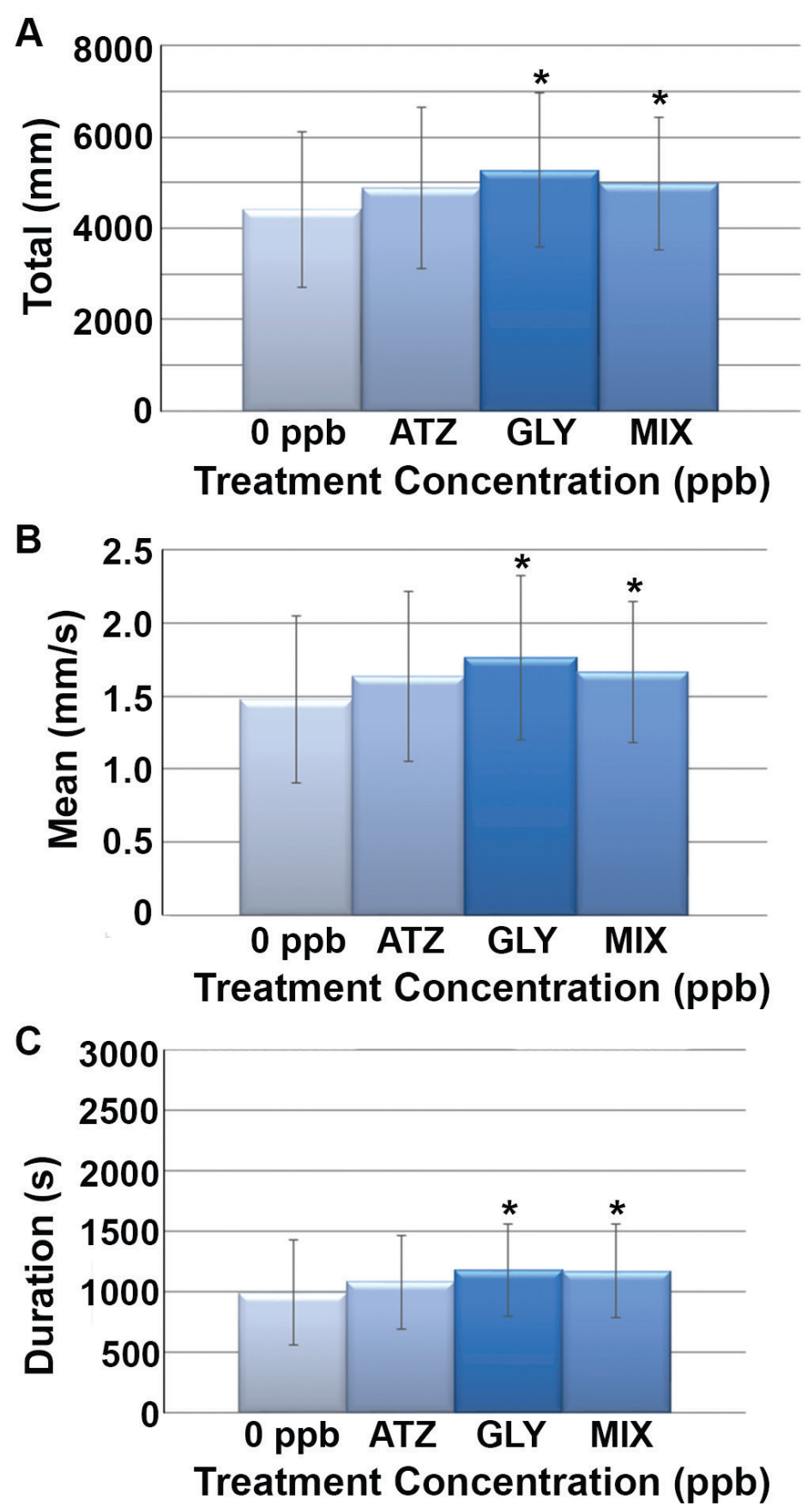

Glyphosate and Atrazine Behavioral Analysis. At 120 hours post fertilization the behavior results for total distance moved $(A)$, velocity $(B)$, and time spent moving $(C)$ showed that the $700 \mathrm{ppb}$ glyphosate and mixture treatment groups were significantly different from the control (*p $<0.05 ; \mathrm{n}=4$ with 24 subsamples/biological replicate; ATZ: 3 ppb atrazine; GLY: 700 ppb glyphosate; MIX: 3 ppb atrazine and 700 ppb glyphosate mixture). 